Portland State University

PDXScholar

Fall 1-2-2019

\title{
Evaluating the Impact and Distribution of Stormwater Green Infrastructure on Watershed Outflow
}

\author{
Benjamin Fahy \\ Portland State University
}

Follow this and additional works at: https://pdxscholar.library.pdx.edu/open_access_etds

Part of the Geography Commons, and the Hydrology Commons

Let us know how access to this document benefits you.

\section{Recommended Citation}

Fahy, Benjamin, "Evaluating the Impact and Distribution of Stormwater Green Infrastructure on Watershed Outflow" (2019). Dissertations and Theses. Paper 4732.

https://doi.org/10.15760/etd.6616

This Thesis is brought to you for free and open access. It has been accepted for inclusion in Dissertations and Theses by an authorized administrator of PDXScholar. Please contact us if we can make this document more accessible: pdxscholar@pdx.edu. 
Evaluating the Impact and Distribution of

Stormwater Green Infrastructure on Watershed Outflow

by

Benjamin Fahy

A thesis submitted in partial fulfillment of the requirements for the degree of

Master of Science

in

Geography

Thesis Committee:

Heejun Chang, Chair

Paul Loikith

Geoffrey Duh

Portland State University

2018 


\begin{abstract}
Green Stormwater Infrastructure (GSI) has become a popular method in climate adaptation strategies as it is designed to reduce storm runoff under increasing precipitation. In this study, a recently developed neighborhood in Gresham, Oregon hosts a comparison of various GSI projects on runoff dynamics. The study site includes dispersed GSI (rain gardens, retention chambers, green streets) and centralized GSI (bioswales, detention ponds, detention pipes). For the 2017-2018 water year, hourly rainfall and observed discharge data is used to calibrate the EPA's Stormwater Management Model to simulate rainfall-runoff dynamics, achieving a Nash-Sutcliffe efficiency of 0.75 and Probability Bias statistic of 3.3\%. A synthetic scenario analysis quantifies the impact of the study site GSI and compares dispersed and centralized arrangements. Each test was performed under four precipitation scenarios (of differing intensity and duration) for four metrics: runoff ratio, peak discharge, lag time, and flashiness. Design structure has significant impacts, reducing runoff ratio 10 to $20 \%$, reducing peak discharge 26 to $68 \%$, and reducing flashiness index 56 to $70 \%$. There was a reverse impact on lag time, increasing it to 50 to $80 \%$. Distributed GSI outperform centralized structures for all metrics, reducing runoff ratio 22 to $32 \%$, reducing peak discharge 67 to $69 \%$, increasing lag time 133 to $500 \%$, and reducing flashiness index between 32 and $62 \%$. This research serves as a basis for researchers and stormwater managers to understand potential impact of GSI on reducing runoff and downstream flooding in small urban watersheds with frequent rain.
\end{abstract}




\section{Acknowledgements}

Special thanks to Katie Holzer, Deanna Foster, and Torrey Lindbo of the City of Gresham Department of Environmental Services for providing the data and relevant documents, and to Dr. Heejun Chang, Dr. Geoffrey Duh, and Dr. Paul Loikith for assisting with developing research methods and design. Research was supported by the Portland State University Institute for Sustainable Solutions and the Urban Resilience to the Extremes Sustainability Research Network under National Science Foundation grant AGS-1444755. 


\section{Table of Contents}

Abstract...........................................................................

Acknowledgements...........................................................

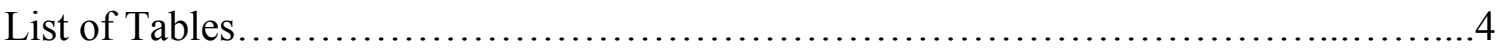

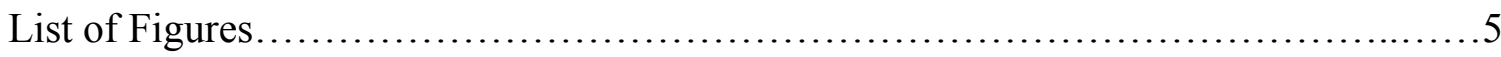

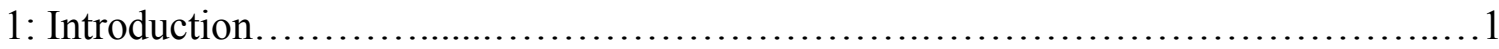

1.1 Nuisance Flooding and GSI..............................................

1.2 The Need for a Sub-catchment Scale Analysis............................. 2

1.3 Cross Comparisons with Land Use and Event Based Climate Scenarios.......6

1.4 Evaluating Spatial Arrangements......................................6

1.5 Utilizing a Hydrologic Model............................................. 7

1.6 Research Questions................................................. 8

2: Study Site and Data Processing............................................

3: Methods................................................................ 13

3.1 Empirical data collection and processing............................. 13

3.2 Preparing SWMM. ................................................ 13

3.3 Sensitivity Analysis................................................ 15



3.5 Simulation Metrics..................................................19

3.6 Scenario Analysis...................................................21

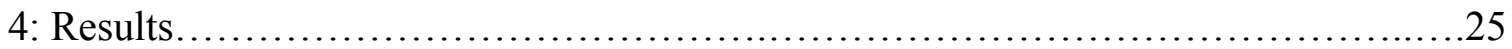

4.1 Sensitivity Analysis............................................... 25

4.2 Model Calibration................................................28

4.3 Scenario Analysis Results..............................................31



6: Limitations and Recommendations.....................................40

References.................................................................... 41

Appendix: Sensitivity using proportions of change in output to input..................48 


\section{List of Tables}

Table 1: Summary and scale related limitations for selected studies 5

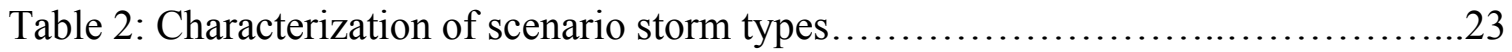

Table 3: Calibration results.......................................................

Table 4: Model Results of no GSI and Brookside GSI................................... 32

Table 5: Model Results of Centralized and dispersed GSI.............................. 


\section{List of Figures}

Figure 1: Photo of Brookside rain garden and construction........................... 10

Figure 2: Study site boundaries, GSI treatment types, and gage locations..............12

Figure 3: Hydrograph showing perturbations in input parameters in SWMM.............16

Figure 4. Hydrograph showing model iterations................................. 18

Figure 5: Framework for second scenario analysis...............................22

Figure 6: Precipitation Scenarios for scenario analyses............................24

Figure 7: Conceptual Diagram of scenario analysis categories..........................24

Figure 8: Impacts of quantitative input parameters..............................27 


\section{Introduction}

\subsection{Nuisance Flooding and GSI}

When landscapes undergo residential development, permeable land is typically replaced with impervious surfaces, increasing the rate and volume of runoff during and after precipitation events (Beebe et al. 2015). High runoff rates cause pipes and storage tanks to overflow, resulting in dispersed flooding and the introduction of potentially harmful substances to stream systems (Chang 2007, Fletcher et al. 2013). Historically, the popular response to mitigating stormwater flooding was increasing capacity of pipes and detention facilities (Shuster et al. 2005). In recent decades however, managers found alternative methods to promote infiltration by diverting runoff through porous vegetation and soil media. (Fletcher et al. 2013). Green Stormwater Infrastructure (GSI), also known as Low Impact Development (LID), Sustainable Urban Drainage Systems (SUDS), Best Management Practices (BMP), and the umbrella term Stormwater Control Measures (SCM), refers to all systems that attempt to promote infiltration and detention of runoff by integrating natural porous surfaces into residential or urban landscapes (Palmer et al. 2015, Golden et al. 2017). GSI has grown in popularity in recent years, as it not only reduces flooding and pollution risk, but is a cheaper alternative to traditional structural methods and includes positive social and ecological benefits such as improving real estate value, reducing obesity, and even mitigating the urban heat island effect (CNT 2010, Wang et al. 2013, García-Cuerva et al.2017). Furthermore, previous studies have predicted that some of the risks GSI is designed to mitigate (flooding and urban heat) may in fact worsen for cities in which a warming global atmosphere would lead to greater precipitation and temperature, and that at the very least, GSI can promote resilience in 
cities where climate change projections signal a greater degree of uncertainty around flooding (Ashley et al. 2005, Gill et al. 2007, Hirabayashi et al. 2013, Demuzere et al. 2014, Matthews et al. 2015).

\subsection{The Need for Subcatchment Scale Analysis}

Although the potential and observed benefits of GSI have been well researched, the optimization of such infrastructure is still largely unknown (Ahiablame et al.2012). In the past, GSI has been evaluated either at a regional scale (i.e. city, metropolitan area), or structural scale (individual structures), leaving a need for sub-catchment scale analyses (Golden et al. 2017).

The first articles evaluating GSI focused on local-scale or plot level sites using laboratory, field study testing, or hydrologic models (Golden et al. 2017). Localized studies can provide key information about the functionality of individual structures and are useful in designing blueprints for implementation. Much of this research compares inflow and outflow metrics for water quality and quantity of individual structures, and any measured changes is attributed solely to the structures (Hunt \& Szpir 2006, Fassman \& Blackbourn 2010, Burns et al. 2012, Jarden et al. 2016). Because many of the aforementioned studies evaluate structures independently, there still exist a need to identify cumulative impacts of combined infrastructure and the effects of different spatial configurations (i.e. proximity to impervious surfaces, to flow accumulation, to other GSI) (Gilroy \& McCuen 2009, Loperfido et al. 2014). Heterogeneity across landscapes can cause uncertainties in assessment and measurement of GSI, even in similar and adjacent areas (Hamel et al. 2013). Measuring functionality at the local scale produces site- 
specific results; variation in runoff response to urbanization depends on physiographical, human mediated and spatial factors of impervious surfaces across the landscape, of which are not consistent across management boundaries (Golden et al. 2017).

Conversely, broader scale comparisons can reduce errors based on spatial and temporal heterogeneity of individual structures, such as soil saturation, antecedent rain conditions and temperature (Thomas et al. 2016). Because agencies responsible for instituting and managing GSI are usually at the city and county levels, regional differences in management allow for comparisons in GSI structure type, arrangement, and density, as well as ownership participation and maintenance, but these analyses typically assume spatial homogenization in otherwise heterogeneous parameters, and are therefore more likely to identify external influential factors (Wainwright et al. 2011, Burns et al. 2012). For example, Baker et al. (2004) studied 515 Midwestern streams and searched for trends in flashiness due to GSI development, with catchments varying from $22 \mathrm{~km}^{2}$ to over $16,000 \mathrm{~km}^{2}$. The authors found watershed area and flow path length far outweighed GSI variation when evaluating catchment flashiness. In a 2016 study by Bell et al. sixteen catchments of up to $33 \mathrm{~km} 2$ were used to evaluate the impact of GSI on runoff, but found only total imperviousness had a significant influence on watershed outflow. In the case of GSI, factors that influence runoff can eclipse GSI when not controlled across comparison groups. Loperfido et al. (2014) attempted to measure GSI by controlling for factors like drainage area, land cover, precipitation patterns, and flood control design standards. Even so, the authors found considerable variation in distribution, connectivity, and density of GSI. Using broad scale watersheds makes it difficult to discern factors (watershed size, impervious surface cover) that influence 
hydrology, even when attempting to control for them in the comparison (Pennino et al. 2016). In sum, large scale analyses allow for identification of statistical correlations between GSI and runoff, but can be preventative at establishing well controlled comparisons (Zellner et al. 2016).

To solve these problems, we seek to focus on subcatchments, which function as hydrologically independent areas with topological characteristics that carry surface flow to a common point that is not necessarily an inlet to a lake or ocean (Martz \& Garbrecht 1992). Metrics like runoff ratio, flashiness indices, and impervious surface percentages are in reference to subcatchment characteristics (Bhaskar et al. 2016). In fact, "catchment capacitance" is a term used to describe the extent to which runoff can be infiltrated, stored, or evaporated, and is key to understanding how GSI can promote stormwater resilience (Miles et al. 2015). Because discharge dynamics represent drainage basins, it is necessary to delineate boundaries that exclude the possibility of water exchange outside of a study site--something that is rarely achieved in local studies. Conversely it is also necessary to isolate GSI in comparisons by controlling for all other variables that influence flow, which can be difficult when regional comparisons are too large to provide accurate accounts of differences in catchments. As shown in Table 1, many of the limitations in local and regional scales are absent for sub-catchment scale studies. The table shows how local scales $\left(<.01 \mathrm{~km}^{2}\right)$ ignore cumulative and interactional effects of GSI, and broad scales $\left(>1 \mathrm{~km}^{2}\right)$ include too many uncontrolled variables. While we acknowledge that there are many studies related to this topic unmentioned in this review, the papers mentioned below identify a general gap in existing literature and support the need for a follow up investigation of GSI at a controlled sub-catchment scale. 







\subsection{Cross Comparisons with Land Use and Event Based Climate Scenarios}

In order to fully understand the relative efficacy of varying spatial arrangements of GSI, multiple climate scenarios should be tested to ensure observed differences are consistent under differing precipitation conditions. Many previous studies on GSI ignore climate scenarios by measuring flow over long term periods of precipitation (Jarden et al. 2016, Thomas et al.2016), or by comparing areas with differences in precipitation patterns (Kim \& Park 2016, Miles \& Band 2015, Albin 2015). This does not allow for conclusions to be drawn between comparison groups on how performance varies with precipitation within the period of analysis.

\subsection{Evaluating Spatial Arrangements}

Optimizing GSI in future projects requires understanding the most effective distribution of structures (Moore et al. 2016, Lim et al. 2016) Once a practitioner and developer identify the size and design standards for GSI facilities, an agreement must be met on how to incorporate the structures among other infrastructure. Champions of GSI must therefore understand the ideal arrangements in a given landscape. While many studies discuss the overall impacts of GSI or compare types of GSI, few evaluate arrangements (Bell et al. 2016, Lim et al. 2016, Golden et al. 2016). Distributed structures have recently been discovered to function more effectively than centralized, treating many smaller surface areas. Even within each general arrangements, there are differing densities of structures that do not necessarily have one to one impacts. The literature has clearly evidenced that there are optimal scales and arrangements for GSI, but few studies have directly addressed this question (Jayasooriya et al. 2014). 


\subsection{Utilizing a Hydrologic Model}

Depending on data availability, some questions can be answered empirically, but to test the impact of multiple spatial arrangements under different climate scenarios, a hydrologic model may be necessary. Across GSI related literature are examples of studies using simulation models to assess the influence of GSI on urban hydrology: in a 2014 study by Jayasooriya et al. twenty simulation modelling tools were evaluated for efficacy in predicting urban runoff mechanics. The Environmental Protection Agency's Stormwater Management Model (SWMM) stood out as the most accurate model for incorporating the complexity of urban systems. SWMM "estimates runoff based on a collection of subcatchment areas that receive rainfall and generate runoff and water quality constituents as influenced by evaporation and infiltration losses from the subcatchments" (Ahiablame et al. 2012). While hydrological models can predict outflow at precise resolutions, there still exist limitations from data availability and "uncertainty of model conceptualizations" (Refsgaard et al. 2016). Many studies calibrate models only to study sites' preliminary conditions before GSI treatment—-such as comparing multiple locations (with controlled variables) or single locations at different points in time (i.e. before/after changes in GSI configuration) (Golden et al. 2017). Furthermore, using models to design GSI to optimize flow can be coupled with economic and social models to encompass cost-benefit analyses (Anderson et al. 2014).

Another need for modelling in the future relates to mixed-land cover study areas and both spatial and temporal variations in land cover characteristics across a catchment (Golden et al. 2017). This is specifically suited to answer questions related to urbanization and the impacts of impervious surface on flow dynamics. While there are 
many models that attempt to answer these questions, SWMM has emerged as the prominent model for urban catchments (Jayasooriya et al. 2012, Golden et al. 2017). If SWMM can be calibrated to empirical data representing multiple arrangements of GSI, coupled with GIS to produce accurate representation, and ran through robust scenario analyses, many of the questions regarding GSI configuration and arrangement can be answered. For these reasons, we will compare different spatial arrangements of GSI in sub-developments in the Brookside Neighborhood in Gresham Oregon. We will use hourly empirical flow and rain data to calibrate SWMM to three catchments at two different points in time. By calibrating to a control site, dispersed GSI site, and centralized GSI site, we can evaluate spatial arrangement scenarios aforementioned in this literature review. Because different arrangements require different costs and time commitments, this research serves as a basis for city planners and developers seeking cost-effective solutions in stormwater management by answering the following questions:

\subsection{Research Questions:}

1) How effective is a combined GSI approach at reducing pluvial nuisance flooding in a climate that receives frequent rainfall?

2) How does a distributed GSI arrangement compare to a centralized arrangement?

3) How does intensity and duration of precipitation impact GSI functionality? 


\section{Study Site}

Issues related to stormwater runoff are more prominent in areas that face high levels of precipitation coupled with land sprawl and riparian development. For this reason, GSI has been a major focus in urbanizing areas of the Pacific Northwest (PNW) where there exists a need to restore natural hydrologic systems and promote infiltration in landscapes becoming dominated by impervious surfaces. The metropolitan area near Portland, Oregon is the second largest in the PNW, with a population of over 2.3 million that grows by over 40,000 people a year (Beebe, 2016). Many local practitioners in Portland metro have recognized GSI investment as a form of mitigating the effects of residential development on flooding, and have worked GSI requirements into local development standards. Documents such as the Portland Water Management Plan (2005), Johnson Creek Watershed Action Plan (2002), and Portland Stormwater Management Manual (2016) include legal requirements for GSI in all future development. In recent years, neighborhoods on the outskirts of Portland experience the largest increases in impervious surfaces near riverine systems, thus posing the greatest threat to natural stream hydrology (Chang and Franczyk 2008, Hoyer and Chang 2014). As stated by the city of Portland and Multnomah County’s 2017 Climate Action Plan Progress Report, "Scientists expect that...Oregonians may see more intense heat waves,... rainstorms, [and] floods in the future" and repeatedly lists flood risk as a potential local threat given climate projections in the United Nation's Intergovernemental Panel on Climate Change 2014 Fifth Assessment Report. It is important to note however that there exists great uncertainty when projecting the impacts of climate change on a local scale, especially at the middle latitudes and under less extreme future scenarios (Jones 2000, Ashley et 
al. 2005, Deser et al.2010). This uncertainty does not however justify disregarding GSI, as building adaptive and resilient cities requires consideration of all potential risks, and should still justify the use of GSI when appropriate (Ashley et al. 2005).

As shown in Figure 1, the Brookside neighborhood in Portland's neighboring Gresham, Oregon is undergoing rapid development projects that will increase impervious surface from less than $3 \%$ to over $45 \%$ in less than a decade (City of Gresham). In response, the City has worked with developers to incorporate GSI projects with the development to reduce runoff into a nearby creek as a means to meet legislative requirements and reduce flooding further downstream.

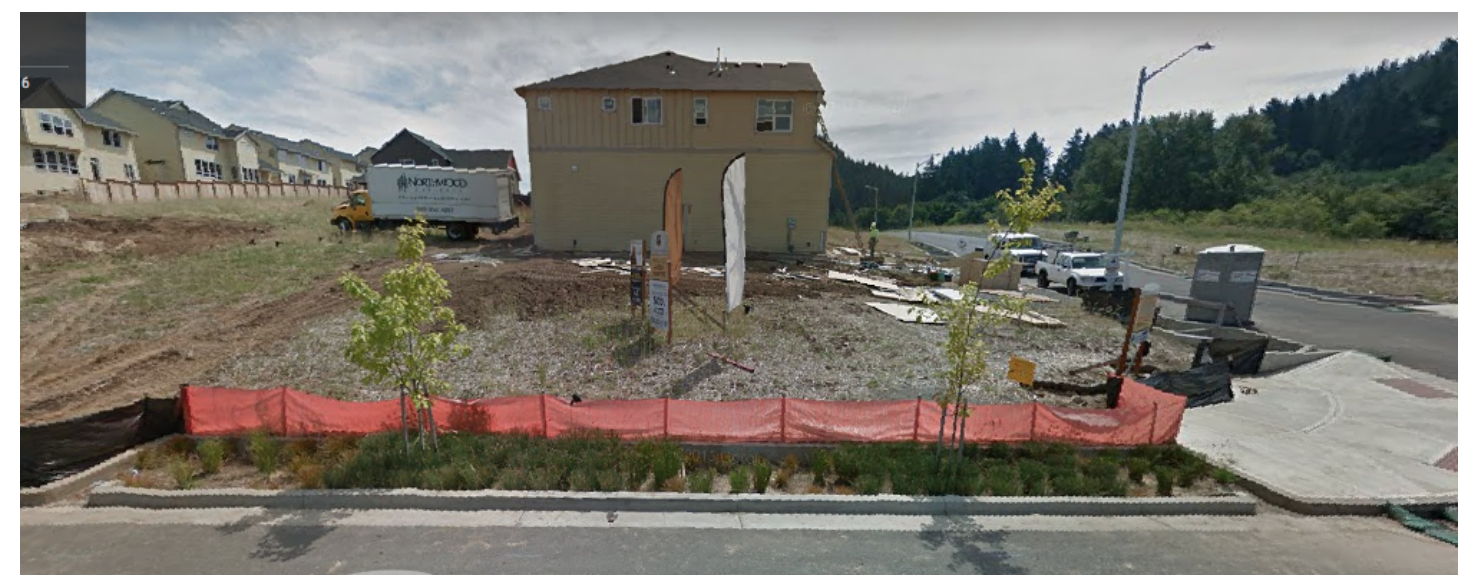

Figure 1: Photo of Brookside rain garden and construction. (Google, 2018)

The Brookside neighborhood functions as a hydrologically independent basin, with runoff generated by either building roofs, driveways, streets, or sidewalks. Runoff from roofs flows either to lot level GSI or driveways or vegetated yards, whereas runoff from driveways, streets, and sidewalks flows to the street, overland along the street, and eventually through street side GSI or manholes that connect to a centralized pipeshed. Brookside is composed of homogeneous infrastructure designs throughout, but with sub- 
neighborhoods that differ in type, arrangement and density of GSI. As shown in Figure 2, subcatchments consist of five residential GSI and three street GSI treatment types contain varying combinations of distributed and centralized structures. The outflow from Brookside is monitored a flow height and velocity data loggers, providing a historical record of discharge. Precipitation data is from the Pleasant Valley School Rain Gage in Gresham (via Portland Hydra Rainfall Network). The westernmost sub-neighborhoods are known as Phase 1 and 2, and contain street side facilities (green streets) but no lot level structures, with flow eventually entering the mainstem pipeshed and connecting to one of two bioswales along the western and southern borders. The large southern bioswale is approximately 30 meters long by 6 meters wide with a ponding depth of just under half a meter, and smaller swale is about 35 meters by 15 meters with a similar ponding depth (City of Gresham). In the center north is the Logan Meadow subneighborhood that contains no dispersed GSI but is treated by a centralized facility known as a Detention Pond, which allows for runoff to pool and accumulate during high flows, initiating infiltration to all water until it pools above the overflow outlet that connects to the mainstem pipeshed. This facility is about 34 meters long by 12 meters wide, with a ponding depth of just over 1 meter (City of Gresham). The northeastern corner of Brookside is treated by no GSI aside from a detention pipe, slowing the flow of runoff in the pipes and allowing for infiltration before flow connects with the mainstem pipeshed. Lastly, Haden's Meadow in the southeastern corner consists of both dispersed and centralized GSI. Right of ways in Haden's meadow contain street side planters, houses contain both rain gardens and infiltration strips/planters, and flow is also connected to the main pipeshed and eventually to the large bioswale. 


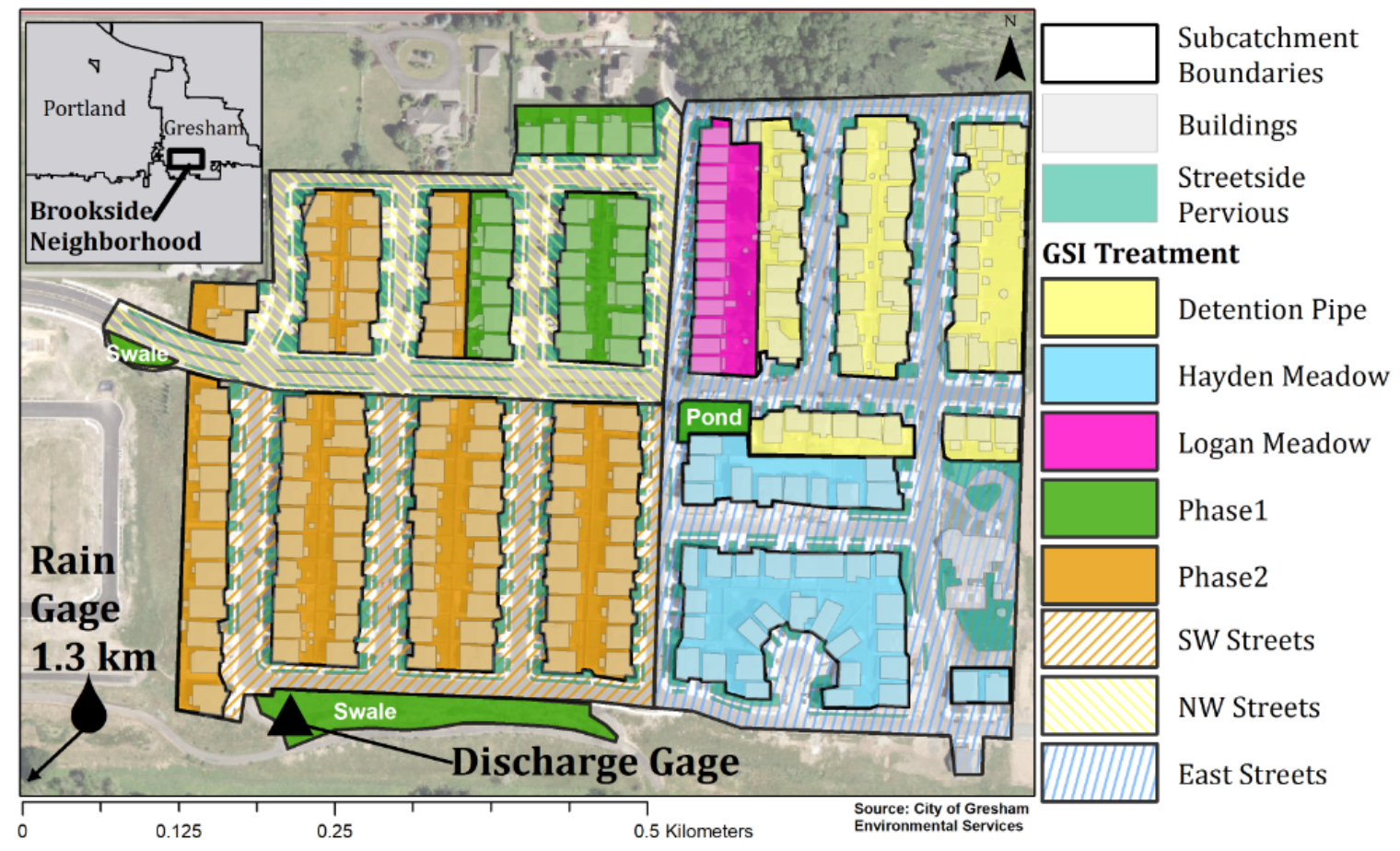

Figure 2: Study site boundaries, GSI treatment types, and gage locations. 


\section{Methods}

\subsection{Empirical Data Collection and Processing}

Prior to calibration, a time period of potential storms was determined from the empirical outflow data provided by the City of Gresham Department of Environmental Services. To ensure consistency, data was selected to consist the maximum number of storms during a period without construction or alterations in the Brookside neighborhood and stormwater infrastructure design. More recent time periods were prioritized as they best represent completed neighborhoods elsewhere. Data from the 2018-2018 rain year (June 1, 2017 to May 1, 2018) was selected. To avoid errors, we removed storms with two minute interval discharge readings greater than quadruple the neighboring values. These values were likely results from errors with the data loggers, perhaps from objects such as sticks causing the flow height gauge to misread water depth. Hourly precipitation data from the rain gage previously mentioned in Figure 2 was matched with outflow data, and was considered accurate for the study site as the rain gage is less than one kilometer away. Because rainfall precedes discharge, rainfall data for 24 hours preceding the date and time of the first non-zero runoff value was included. Two minute outflow data was converted to hourly to match precipitation data, and in turn streamline the calibration process within SWMM.

\subsection{Preparing SWMM}

The first step in building a model to use for sensitivity testing and calibration was to determine all necessary fixed input parameters to model the neighborhood. Site boundaries and flow paths (both surface and pipeshed) were determined using Digital 
Elevation Models (DEMs) at a one meter resolution from the City of Gresham and the Hydrology tool set in the Environmental Systems Research Institute's ArcGIS software. DEMs were processed to produce slope and gradient inputs which are used by SWMM to determine overland and pipe flow dynamics. Buildings, roads, pipes, and GSI structures were delineated using blueprints and high resolution aerial photographs provided by the City of Gresham and Google Earth, 2017. From this, the percentage of impervious surfaces, flow path widths, landscape slopes, and other input parameters were calculated. Flow paths and GSI and building dimensions were ground-truthed to reduce measurement errors as much as possible.

Because SWMM allows multiple options for routing flow, subcatchment design, processing infiltration, and incorporating infrastructure, various theoretical designs and parameters were compared to identify a model with the least amount of error. For flow routing, SWMM can be programmed to direct runoff between catchments, from catchments to pipes or outfalls (outlets to the pipe system), from catchments to junctions (nodes connecting pipes, manholes, or outfalls), between junctions via pipes, and from pipes to outfalls. For subcatchment design, subcatchments can be used to model individual lots, blocks of houses, entire neighborhoods, or even entire cities or counties. For infiltration processing, the model can use either a Hortonian flow, Green-Ampt, uniform loss, or a SCS curve number method. Each model differs in how infiltration is processed on a cell by cell basis during overland flow. For incorporating infrastructure, SWMM can consider GSI as a structure occupying a percentage of a catchment along a flow path downstream from other catchments, or as a treatment parameter to an upstream catchment. For example, a residential catchment can be routed through a small catchment 
modelling a bioswale, or can be assigned a bioswale treatment before it reaches the outlet. While different courses and combinations of such structures may represent the physical landscape equally, these settings can produce different model outputs and were therefore tested as the first step in the calibration process. In the case of Brookside, the most accurate model routed flow from residential catchments with lot level GSI treatment bioswales and detention ponds catchments to outfall nodes. Pipes, junctions, and the consideration of centralized GSI as a treatment to residential catchments producing less accurate results and were therefore omitted for the remainder of this study.

\subsection{Sensitivity Analysis}

Prior to calibration, a sensitivity analysis was ran to understand which parameters were dominating the outputs of the model. To identify such parameters, preliminary testing and the review of two past SWMM sensitivity analyses (Tsihrintzis et al.1998, Tsai et al.2017) yielded a list of fourteen variables that significantly impacted model performance (in order of most to least sensitive: subarea routing, GSI outflow routing, monthly evaporation constant, width of overland flow, evaporation method, impervious depression storage, Manning's N (impervious), \% zero imperviousness, pervious depression storage, Manning's N (pervious), infiltration routing method, conductivity constant, suction head, and initial moisture deficit). Parameters were then altered independently of one another against the original base model designed with fixed (empirically measured) input parameters and suggested variable parameters from the SWMM user manual. The sensitivity analysis identified which parameters had the greatest impact on model performance, and were refined in order of decreasing impact to 
the model during the calibration phase.

To determine the order of parameters with the greatest model sensitivity, parameters were first grouped into qualitative and nominal inputs (with limited nonnumerical settings) and quantitative inputs (numerical values). Although qualitative inputs were tested during this analysis to confirm model sensitivity, each setting for all parameters was evaluated during calibration and are therefore not reported otherwise. Each quantitative parameter was tested for six different perturbations of the SWMM manual suggested values (as ten, twenty, and thirty percent increases and decreases to the default), illustrated with an example of Impervious Depression Storage in Figure 3 below.

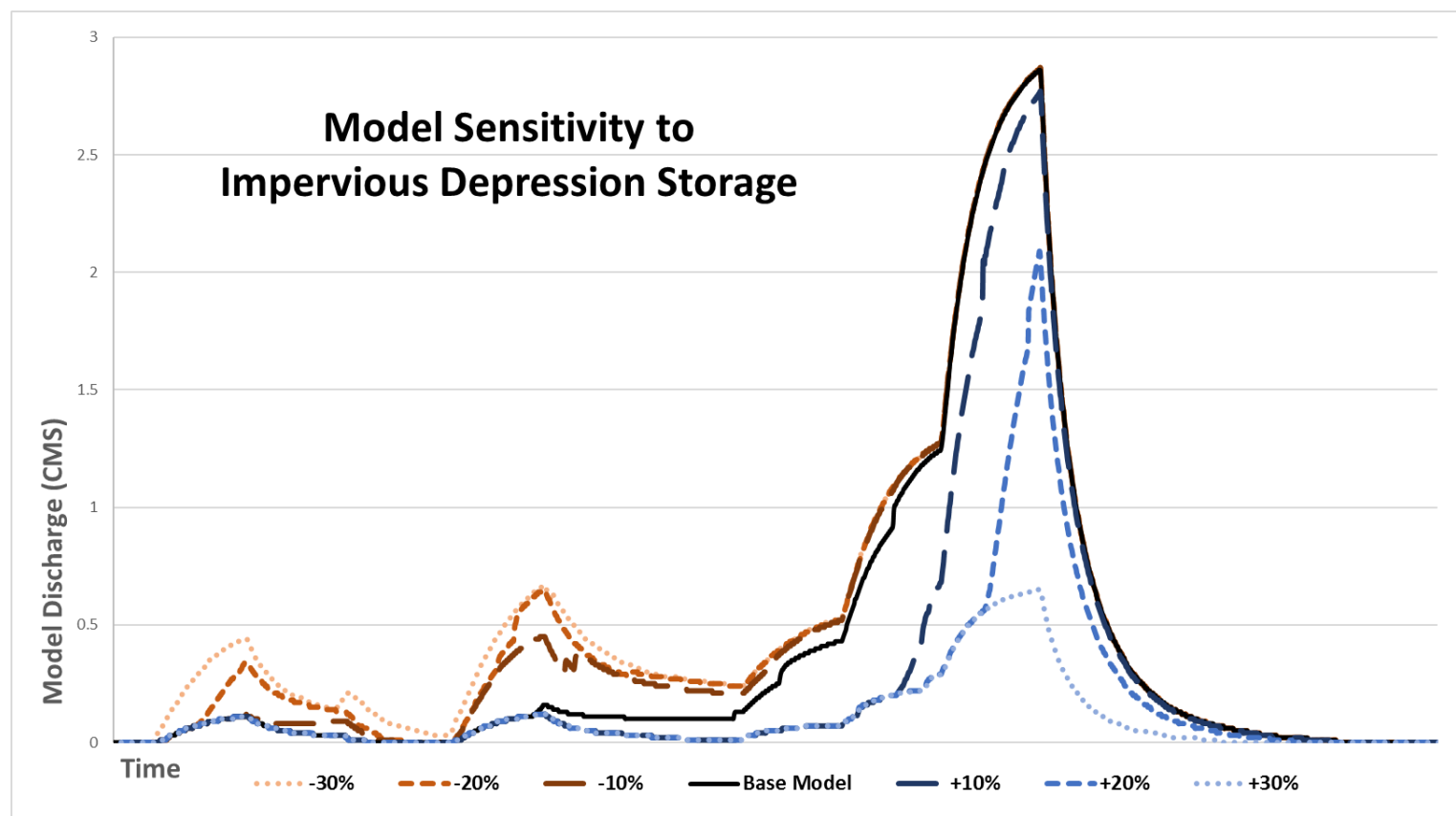

Figure 3: Hydrograph showing perturbations in input parameters in SWMM. 


\subsection{Calibration and Validation}

After selecting the water year for calibration, SWMM was used to simulate rainfall-runoff interactions and the process of altering the model's parameters to calibrate it to empirical data began. Although SWMM offers an automated calibration process, this process requires individual subcatchment runoff values, and cannot be used for a system of multiple subcatchments as used in this study. For that reason, a manual calibration process was used to improve model performance by manually adjusting one variable input parameter at a time. Precipitation data and monthly historical evaporation data were the only inputs required for model calibration. Beginning with the base model from section 3.2, each step during calibration adjusted one parameter at a time, mostly in decreasing order of the most sensitive parameters via the sensitivity analysis (occasionally a less-sensitive parameter was optimized before a more-sensitive parameter when the influence on model calibration was greater. This occurred mostly because the sensitivity analysis did not always capture the range of values in which parameters could be adjusted, leading some less sensitive parameters to have greater impacts on calibration metrics). Figure 4 uses an example of three subsequent models to illustrate how each adjustment to inputs improve the model's ability to match observed outflow data. 


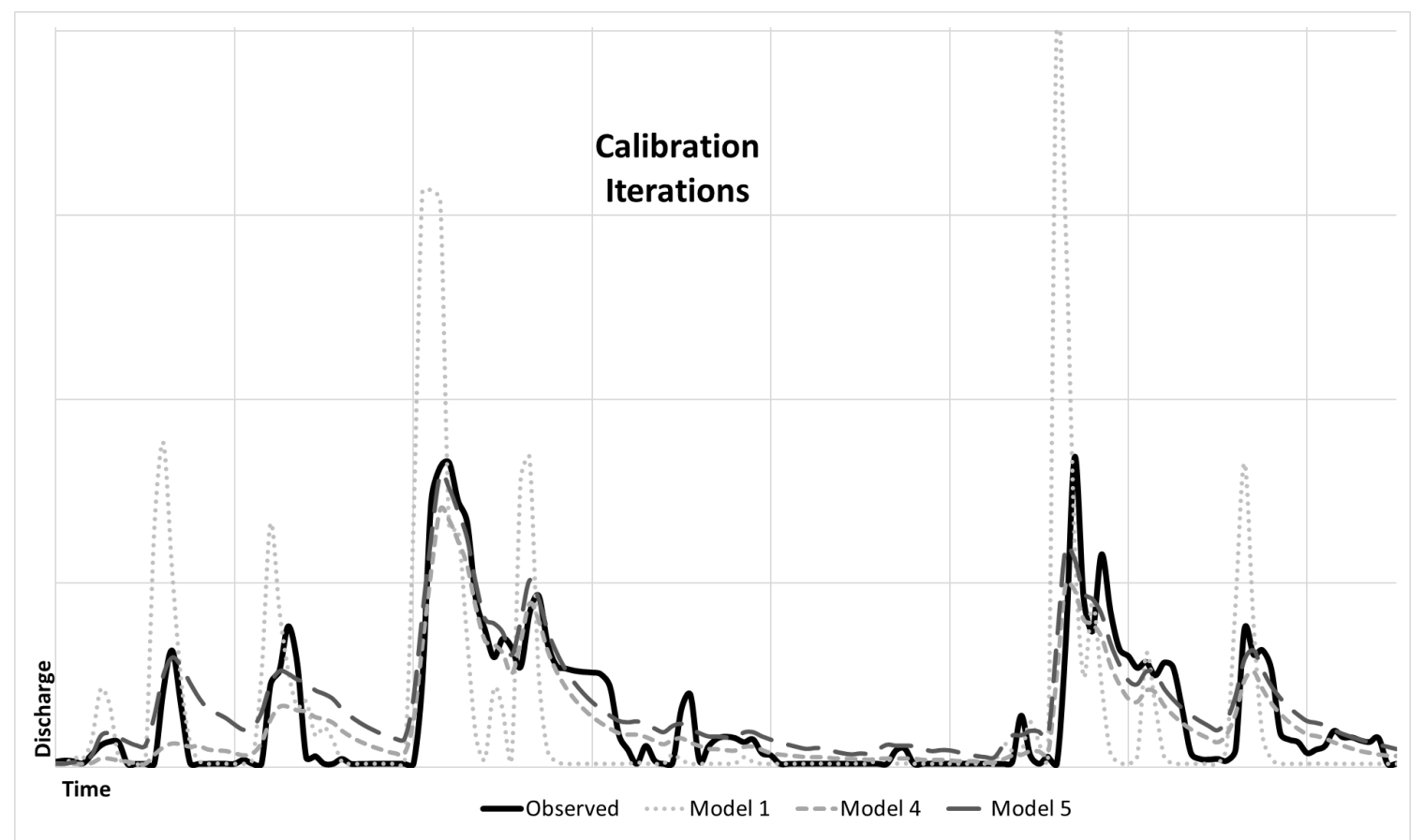

Figure 4: Hydrograph showing model iterations.

The model's outflow hydrograph for the selected water year was first used to compute a Nash-Sutcliffe Equilibrium (NSE) statistic, a metric for optimizing the model for each given input parameter. The NSE is determines the extent of the residual variance (or "noise") compared to the variance of the empirical data (Nash and Sutcliffe, 1970). In sum, NSE measures how well the modeled to empirical data fits a 1:1 line. NSE ranges between $-\infty$ and 1 , with values between 0 and 1 being acceptable, and higher values signaling stronger performance (Moriasi et al. 2007). Once the model was calibrated to optimize NSE, the Probability Bias (PBIAS) statistic was used for verification, and was only tested for the final model (and the base model for comparison). Unlike NSE, PBIAS measures the tendency of the model output to differ from the empirical data. The optimal value of PBIAS is 0 , with low-magnitude (absolute value) measurements indicating 
accuracy (Gupta et al. 1999). NSE and PBIAS can be considered satisfactory if NSE > 0.5 , and if PBIAS is within 25\% (Moriasi et al. 2007). Once calibrated and verified using the NSE and PBIAS statistics, the refined model was used simulate scenario storms in order to test GSI performance in Brookside, as well as alternate arrangement strategies.

\subsection{Simulation Metrics}

The calibrated model was used to run a series of simulations to test the effects of different types, spatial arrangements, and densities of GSI on flooding potential. Outlined below are the four different variables used as metrics for comparison, and an explanation for why they represent potential risks associated with nuisance flooding.

\subsubsection{Runoff Ratio}

Runoff Ratio (also known as Rainfall Runoff Ratio or RRR) is similar to total discharge in that it is a measure of the total quantity of precipitation that fails to infiltrate, evaporate, or increase storage during a storm event (see equation below). Using a ratio adjusts for small alterations to landscapes in different scenarios that may change the total volume of precipitation entering the system. Because downstream flooding can reduced by preventing large quantities of discharge from entering waterways, understanding how much water GSI can potentially detain from a riverine system during a flood event can lend knowledge towards the ability for GSI to mitigate flooding (Johnson Creek, 2005).

$$
\text { Runoff Ratio }=\frac{\int_{\text {start }}^{\text {end }} \text { flow }(\text { time }) d_{\text {time }}}{\int_{\text {start }}^{\text {end }} \text { precipitation }(\text { time }) d_{\text {time }}}
$$




\subsubsection{Variable 1: Peak Discharge}

Peak discharge is the maximum of the instantaneous peak flow (cubic meters per second) in the hydrographs of simulation events, as shown in the equation below. Because peak flow can lead to combined sewer overflow (CSO) and thus both flooding and water quality problems, peak discharge will be compared across GSI arrangments to understand different CSO mitigation potentials (Combined, 2015).

$$
\text { Peak Flow }=\max \left\{\text { flow }(\text { time }): \text { time }_{\in}\left[\text { storm }_{\text {start }}, \text { storm }_{\text {end }}\right]\right\}
$$

\subsubsection{Lag Time}

Lag time is calculated to help identify predictors or indicators between two variables, in this case precipitation and discharge (Cross, 2007). By using the lag-to-peak method outlined in Hood et al.(2007), lag time was calculated as the difference in time from the first onset of precipitation to peak discharge, and is shown in equation below. As shorter lag times typically correspond with greater imperviousness and less capability to capture runoff, lag time can be a good proxy for understanding flood potential (Cross, 2007).

Lag Time $=$ distance $\left\{\right.$ time $_{\text {first peak discharge }}-$ time $\left._{\text {first nonzero precipitation }}\right\}$

\subsubsection{Flashiness Index}

The shape of hydrograph will serve as a basis to compare flashiness; because flashy hydrographs depict sharp vertical jumps and steep vertical declines, the slope of the maximum tangent line along the first rising limb will be computed and used for 
comparison (see equation below). Development and impervious surfaces can exacerbate flashiness and increase the rate at which water enters pipes, water treatment facilities, and stream networks, thus leading to higher discharge downstream (Baker et al. 2014).

$$
\text { Flashiness Index }=\max \left\{\lim _{x \rightarrow 0}\{\lim (\text { time }+x)-f \operatorname{low}(\text { time })\} / x\right.
$$

\subsection{Scenario Analysis}

In order to identify the most effective arrangements of GSI and under which conditions they are most effective, we use a synthetic scenario analysis to perform two tests: first, to quantify the impact of GSI in the Brookside neighborhood against an absence of GSI; and second, to compare performance of dispersed vs. centralized GSI. In the first analysis, the Brookside arrangement is represented by the calibrated model from the calibration phase. The No GSI model is designed exactly as Brookside with all GSI (both centralized and dispersed structures) removed. For the second test, two synthetic neighborhoods were designed to compare the performance of completely dispersed and completely centralized GSI designs (Figure 3). For the centralized scenario, dispersed GSI was removed, and new centralized structures (bioswales, detention pipes, and detention ponds) were applied to regions previously treated by dispersed structures. Conversely, for the dispersed arrangement, all centralized facilities were removed and replaced by dispersed structures in order to mimic treatment in the dispersed GSI regions. 


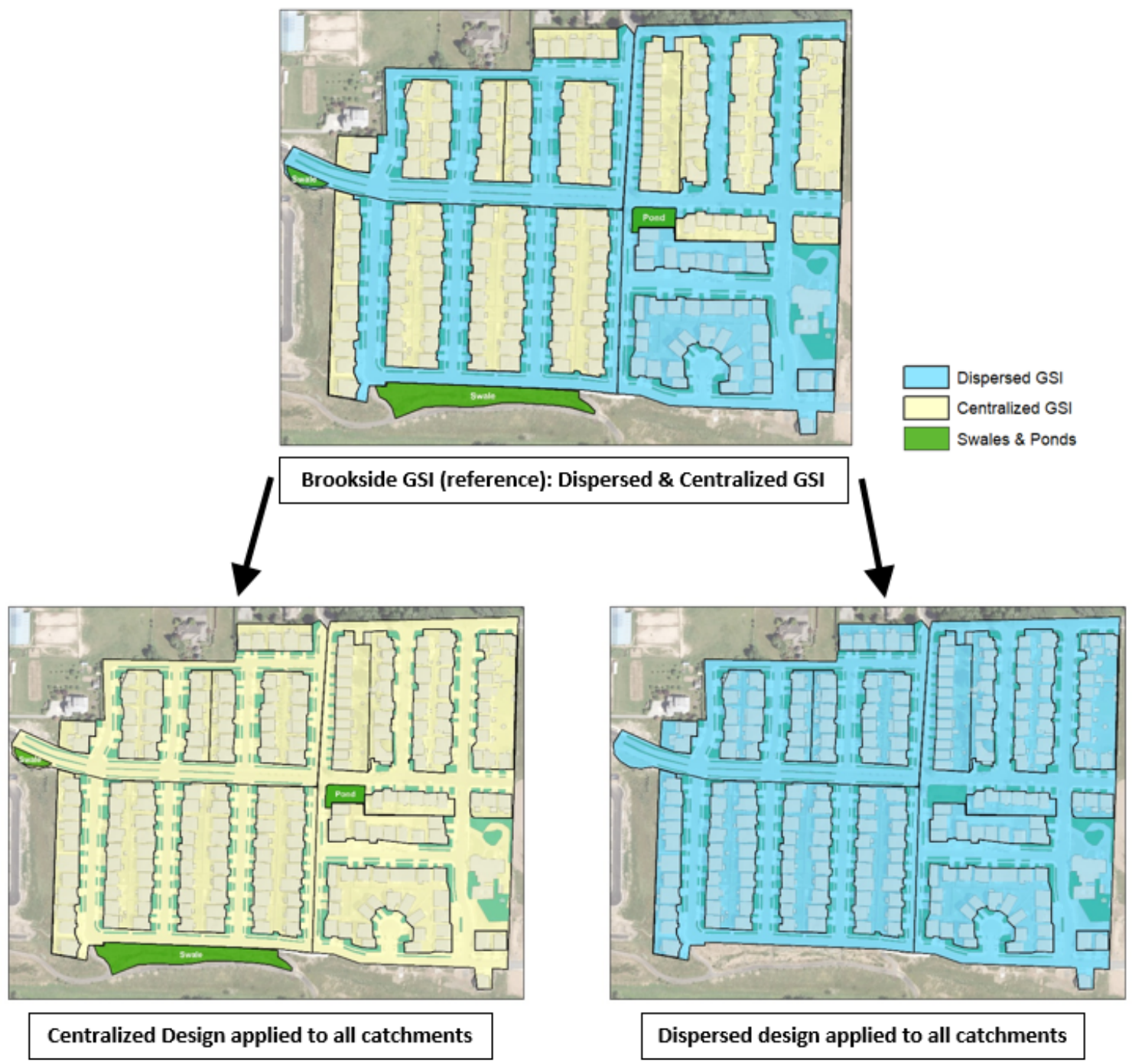

Figure 5: Framework for second scenario analysis.

All tests evaluated four synthetic precipitation events including two levels of both precipitation volume and duration to measure the directional relationship of storm type and performance of the GSI arrangement in question (Table 2). Precipitation values were based on historical rainfall data from Portland HYDRA Rainfall Network, and validated with precipitation Intensity-Duration-Frequency (IDF) curve values from the 2007 Portland Bureau of Environmental Services Sewer Drainage Facilities Design Manual 
and 2013 Stormwater Management Facilities Monitoring Report. The former defines a 2 year 24 hour storm event with $0.254 \mathrm{~cm} / \mathrm{hr}$ average precipitation, and the later references design storms ranging from $0.087 \mathrm{~cm} / \mathrm{hr}$ to $0.800 \mathrm{~cm} / \mathrm{hr}$ with peak intensity starting at $0.432 \mathrm{~cm} / \mathrm{hr}$ for 24 hour events, thereby validating the selected scenario storms used in this analysis. Holding precipitation volume constant to 1.83 and $3.66 \mathrm{~cm}$, storm durations of 16 and 32 hours were tested. As shown in Figure 6, long duration events are double that of short events with two consecutive hours of half the rainfall for a given hour in a short duration event.

Table 2: Characterization of scenario storm types.

\begin{tabular}{l|cccc} 
Storm Type & $\begin{array}{c}\text { Total } \\
\text { Precipitation } \\
\text { (cm) }\end{array}$ & $\begin{array}{c}\text { Total } \\
\text { Duration } \\
\text { (hours) }\end{array}$ & $\begin{array}{c}\text { Average } \\
\text { Precipitation } \\
\text { cm/hour }\end{array}$ & $\begin{array}{c}\text { Max } \\
\text { Precipitation } \\
\text { cm/hour }\end{array}$ \\
\hline $\begin{array}{l}\text { Low volume, short } \\
\text { duration }\end{array}$ & 1.83 & 16 & 0.114 & 0.203 \\
$\begin{array}{l}\text { Low volume, long } \\
\text { duration }\end{array}$ & 1.83 & 32 & 0.057 & 0.102 \\
$\begin{array}{l}\text { High volume, short } \\
\text { duration }\end{array}$ & 3.66 & 16 & 0.229 & 0.406 \\
$\begin{array}{l}\text { High volume, long } \\
\text { duration }\end{array}$ & 3.66 & 32 & 0.114 & 0.203
\end{tabular}




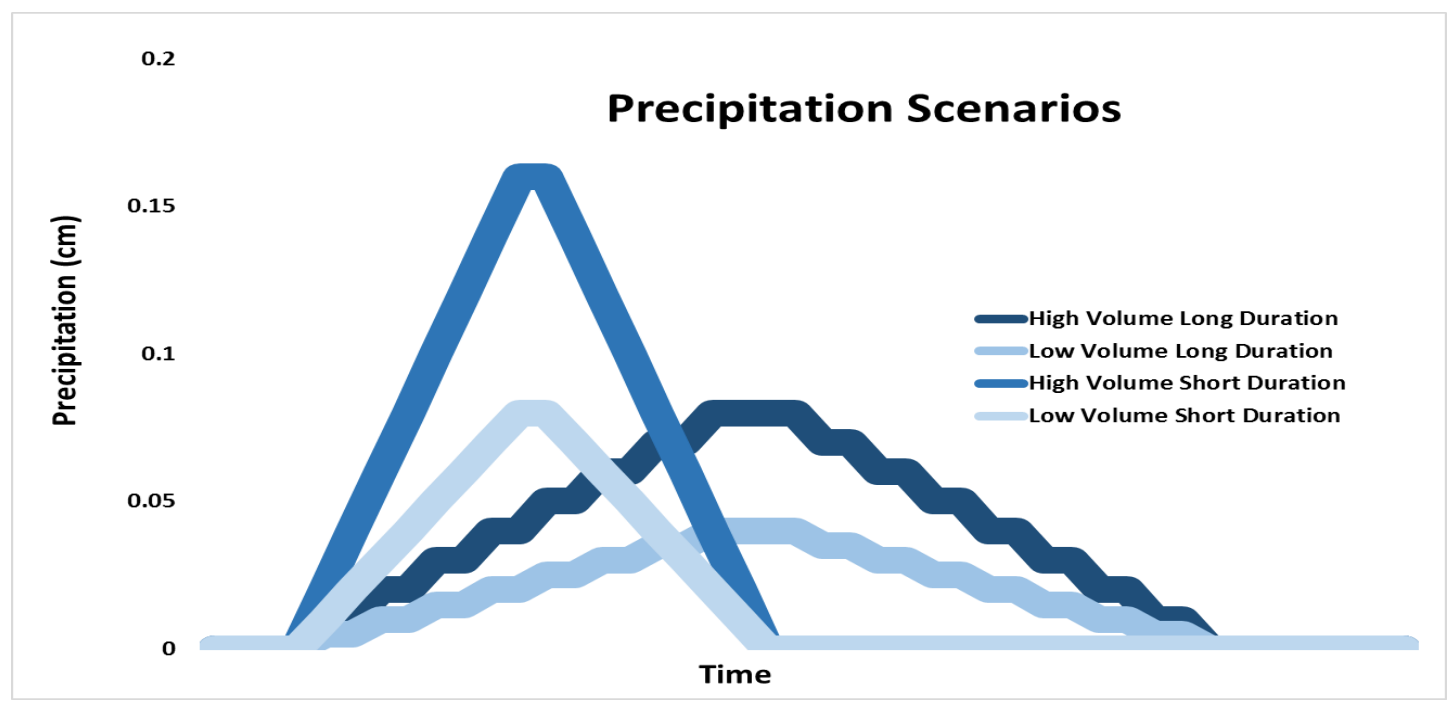

Figure 6: Precipitation Scenarios for scenario analyses.

By testing four storm types for four metrics for two arrangements, both scenario analyses consisted of sixteen simulations (Figure 7). Differences between arrangements were calculated as percent change from one arrangement to the other (from no GSI to Brookside GSI and from centralized GSI to dispersed GSI) to quantify the extent to which one arrangement outperformed the other for each metric.

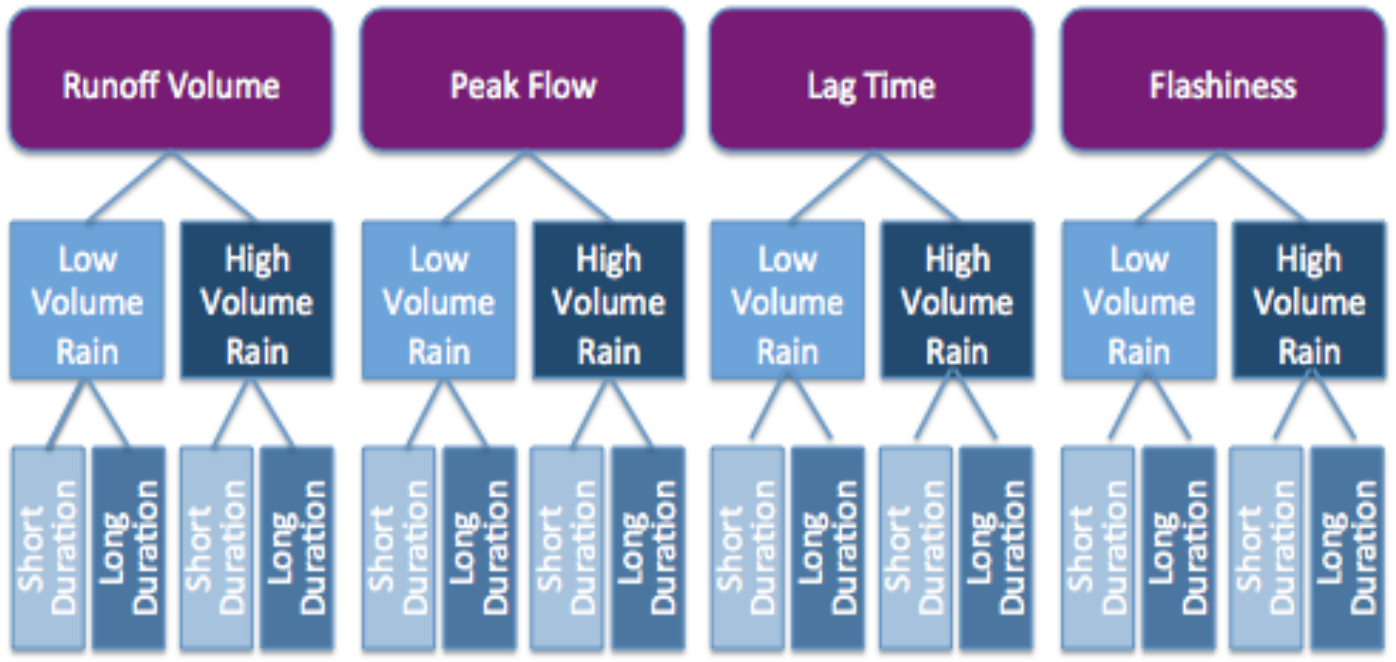

Figure 7: Conceptual Diagram of scenario analysis categories. 


\section{Results}

\subsection{Sensitivity Analysis}

For the qualitative parameters, the most sensitive parameters were evaporation method, followed by GSI outflow routing method, subarea routing method, and the type of infiltration routing method. GSI outflow routing and subarea routing were found to have significant impacts on runoff for similar reasons. GSI outflow routing decreased runoff by roughly $95 \%$ when outflow was returned to permeable areas because runoff is redirected to permeable regions before exiting each catchment, providing flow an opportunity to infiltrate. Similarly, subarea routing had a positive impact, increasing runoff by $49 \%$ when switched from impervious to pervious routing because it routes all flow from impervious areas not directly connected to the outfall back to permeable areas. For evaporation method, empirically based (monthly average and daily temperature based) models were found to increase runoff by $8.6 \%$ and $4.3 \%$ respectively, likely because using monthly averages of 0.25 inches per day (SWMM manual default) overestimates evaporation and underestimates runoff during colder and wetter months such as the fall, winter, and spring months during a water year. Lastly, when the model's infiltration method was switched from the default Modified Green-Ampt infiltration model to Hortonion and curve number methods, we saw a decrease of $0.1 \%$ and an increase of $2.7 \%$ respectively. This is because Green Ampt assumes a wetting front that separates soil types, and Hortonion assumes exponential decrease in infiltration for soil, such that switching to the Hortonion reduces limits in infiltration from Green Ampt which then reduces runoff in the Hortonion model. Nevertheless, it is sensitivity to a small extent. Changing the method to curve number increased runoff likely because curve 
number assumes a capacity as a function of rainfall, thus more likely to prevent infiltration during rain events, leading to greater runoff volumes (Dickinson 2017).

The order of quantitative parameters with the greatest model sensitivity is shown in Figure 8, with supporting data in Appendix A. Unsurprisingly, as evaporation has a direct impact on the model's processing of diminution of overland flow with time, monthly evaporation constants were the most sensitive parameter used in the analysis, with outputs changing at about $19 \%$ of the relative change to the input parameter for all perturbations $( \pm 10, \pm 20$, and $\pm 30 \%)$. Although evaporation rate may seem like a fixed variable that should be set using empirical measurements, accuracy with evaporation is difficult to ascertain, thus prompting a need to test's its relative sensitivity to the model to direct calibration. The next most sensitive parameter, Impervious Depression Storage, is inversely sensitive with relative changes to outputs averaging about $5.4 \%$ of that of inputs for all perturbations. This is because Brookside is mostly composed of impervious high density residential housing, and is the single input variable that determines losses from impervious surfaces; the greater the storage, the less runoff. Following is percent zero imperviousness, affecting model runoff on average about $3.2 \%$ of in the relative change for all perturbations for similar reasons to that of the sensitivity of impervious depression storage: this metric determines the percentage of impervious area with zero depression storage, thus an increase in this percentage would cause less storage and greater runoff. For infiltration parameters, conductivity constant was found to impact runoff inversely, averaging a relative reduction in runoff of $2.5 \%$ for all perturbations, as water conductivity of soil and permeable surfaces can increase infiltration and remove runoff, but the sensitivity was much less, as the study site is largely composed of impervious 
surfaces. Changes in width of overland flow corresponded to a relative $1.2 \%$ change in outflow on average for all perturbations. As width of flow increases, the time for runoff to move across a surface increases thus causing an increase in infiltration, evaporation and runoff. The last quantitative parameter found to have significant impact on the model is Manning's N, despite usually being a parameter that impacts peak and shape more than volume. Changes in Manning's $\mathrm{N}$ corresponded to averages of $1 \%$ reductions in flow for all perturbations, likely because this parameter affects the time it takes for overland flow to reach the outfall, thus increasing the time flow is available for evaporation and infiltration, thus reducing runoff.

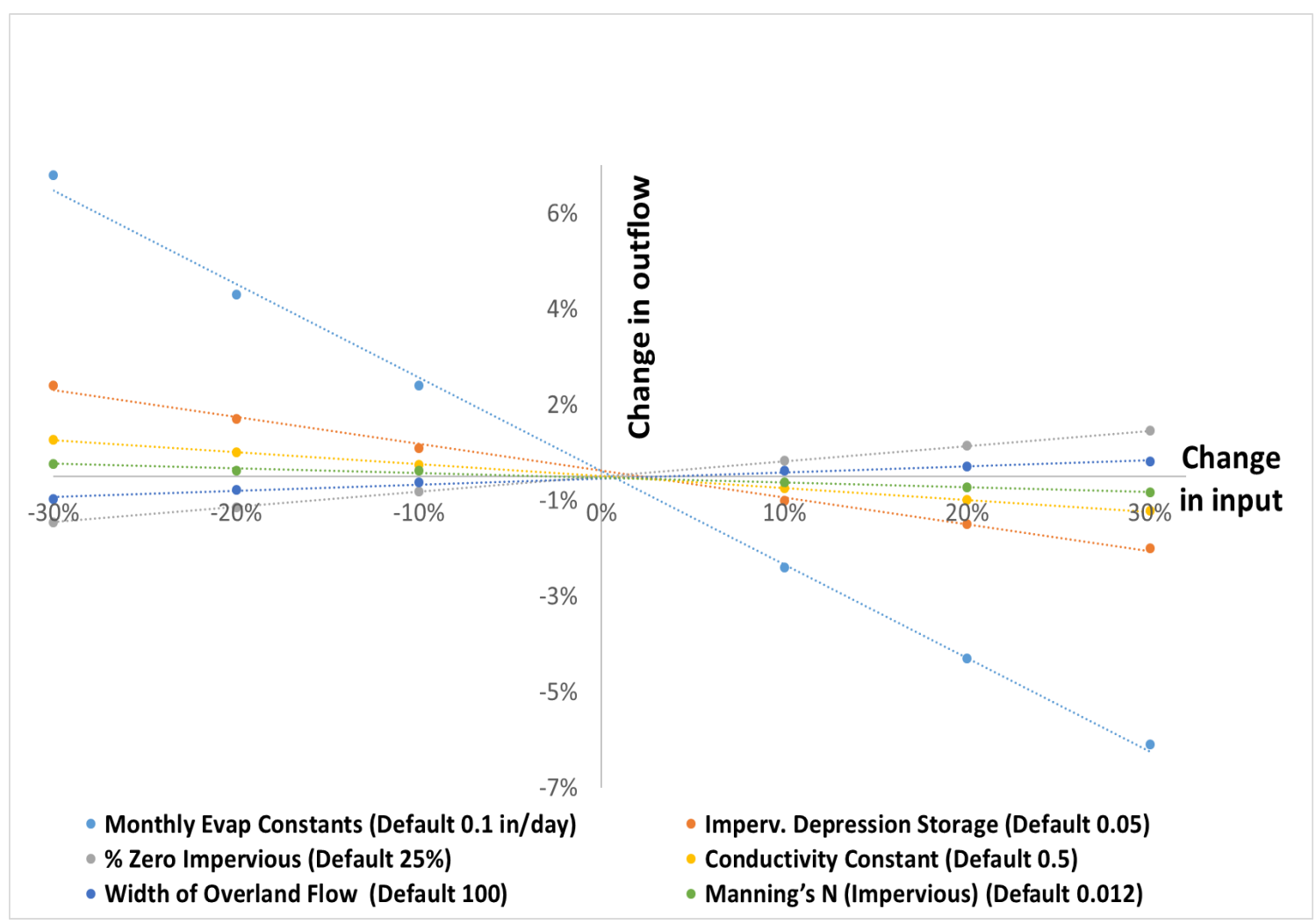

Figure 8: Impacts of quantitative input parameters. 
The results of our sensitivity analysis were only partially aligned with similar tests in previous findings using SWMM to model catchment hydrology. As found by Tsihrintzis et al.1998, sensitive variable input parameters (in order of most to least sensitive) were Impervious Depression Storage, Pervious Depression Storage, and Manning's N. As found in Tsai et al.(2017), SWMM is sensitive to infiltration metrics such as suction head, conductivity constant, and initial moisture deficit, as well as depression storage and Manning's $\mathrm{N}$ for overland flow. Other research papers have identified parameters that are not relevant or applicable given the context of this study (McCuen et al. 1973, Wang et al. 2008, Song et al. 2015).

\subsection{Model Calibration}

Model calibration was performed for all parameters by adjusting one at a time, in order of greatest impact on the calibration metrics as explained in section 3.4. As shown in Table 3, subsequent rows correspond to increasing NSE values that illustrate improvements in model accuracy via calibration for the given parameter. Because only one statistic can be used to direct calibration, PBIAS was calculated only to verify model accuracy, and was not considered during intermediate steps. Beginning with base model, both NSE and PBIAS were insignificant at 0.291 and $4.10 \%$ respectively, showing that moving averages calculated directly from empirical data are nearly as strong of predictors as simulated values (low NSE), and that the average tendency of the simulated data is to predict lower flows than that of the empirical data (positive PBIAS), known as model underestimation bias (Gupta et al. 1999). Adjustments to Subarea routing and GSI outflow routing did not improve the model's NSE scores and were therefore left as 
default values, likely because flow from Brookside is primarily channeled across impervious surfaces to the outfall once it reaches any given impervious surface. Optimizing for evaporation by testing a series of deviations from the SWMM manual's suggested value of 0.25 centimeters per day found the most calibrated constant evaporation rate to be 0.28 centimeters per day, yielding an NSE of 0.398 . Reducing width of overland flow significantly improved the model's NSE score to 0.670 , likely correcting underestimates of infiltration by routing overland flow too quickly over impervious surfaces. The calibrated monthly average value for evaporation was outperformed by using historical monthly averages (achieving an NSE of 0.675) for Portland via the National Atmospheric and Oceanic Sciences WS 34 report (Farnsworth \& Thompson, 1982), allowing for corrective simulations of evaporation-and thus runoffon a month by month basis to account for seasonal changes throughout the water year. Calibrating for IMD and Manning's N for impervious surfaces further improved NSE to 0.687 and 0.745 respectively, as these metrics eliminated the model's previous inability to account for depressions in pavement and roughness throughout the Brookside neighborhood. Optimizing for percent of the landscape without imperviousness improved NSE to 0.754 as the default was overestimating the extent of imperviousness in the study site. Lastly, calibrating for infiltration methods and corresponding inputs (conductivity constant, suction head, and initial soil moisture deficit) showed that default values performed best or that perturbations of these values had little to no impact on model performance (only slightly improving NSE to 0.756 ). A final verification with PBIAS shows that calibrated model illustrating that only 3.30\% (an improvement from the base model) of the simulated data is significantly deviating from the empirical data. 
Table 3: Calibration results.

\begin{tabular}{|c|c|c|}
\hline Parameter & $N S E$ & PBIAS (\%) \\
\hline $\begin{array}{l}\text { Base model } \\
\text { (used in sensitivity analysis) }\end{array}$ & 0.291 & 4.10 \\
\hline $\begin{array}{l}\text { Subarea routing } \\
\text { (Value selected }{ }^{*}: \text { impervious) }\end{array}$ & 0.291 & 4.10 \\
\hline $\begin{array}{l}\text { GSI outflow routing } \\
\text { (Value selected } * \text { do not return flow) }\end{array}$ & 0.291 & 4.10 \\
\hline $\begin{array}{l}\text { Monthly evaporation constant } \\
\text { (Value selected: } \mathbf{0 . 2 8} \mathbf{~ c m} / \mathbf{d a y} \text { ) }\end{array}$ & 0.398 & -3.69 \\
\hline $\begin{array}{l}\text { Width of overland flow } \\
\text { (Value selected: } \mathbf{3 0 5} \mathbf{~ m} \text { ) }\end{array}$ & 0.670 & 11.5 \\
\hline $\begin{array}{l}\text { Evaporation method } \\
\text { (Value selected: monthly averages) }\end{array}$ & 0.675 & -2.05 \\
\hline $\begin{array}{l}\text { Impervious depression storage } \\
\text { (Value selected }: \mathbf{3 . 8 1} \mathbf{~ m m} \text { ) }\end{array}$ & 0.687 & 1.11 \\
\hline $\begin{array}{l}\text { Manning's N (impervious) } \\
\text { (Value selected: 0.024) }\end{array}$ & 0.745 & 3.44 \\
\hline $\begin{array}{l}\text { \% Zero impervious } \\
\text { (Value selected: } \mathbf{2 1 \%} \text { ) }\end{array}$ & 0.754 & 3.27 \\
\hline $\begin{array}{l}\text { Pervious depression storage } \\
\text { (Value selected }: \mathbf{2 . 5 4} \mathbf{~ m m} \text { ) }\end{array}$ & 0.755 & 3.27 \\
\hline $\begin{array}{l}\text { Manning's N (pervious) } \\
\text { (Value selected } *: 0.15 \text { ) }\end{array}$ & 0.755 & 3.23 \\
\hline $\begin{array}{l}\text { Infiltration Routing Method } \\
\text { (Value selected }{ }^{*} \text { Modified Green-Ampt) }\end{array}$ & 0.755 & 3.23 \\
\hline $\begin{array}{l}\text { Conductivity constant } \\
\text { (Value selected: 0.6) }\end{array}$ & 0.756 & 3.31 \\
\hline $\begin{array}{l}\text { Suction head } \\
\text { (Value selected }^{* *}: \mathbf{3 . 8} \text { ) }\end{array}$ & 0.756 & 3.30 \\
\hline $\begin{array}{l}\text { Initial soil moisture deficit } \\
\text { (Value selected } * *: \mathbf{0 . 2 2 5} \text { ) }\end{array}$ & 0.756 & 3.30 \\
\hline
\end{tabular}

*Value selected was default value used in the base model

**Optimized value had little to no effect on NSE and PBIAS) 


\subsection{Scenario Analysis Results}

Using the final model from the calibration phase to model Brookside, the first of the two GSI arrangement scenario comparisons measures impact of GSI in Brookside by testing the modeled neighborhood with the current GSI arrangement against that with no GSI for four hydrologic metrics, for four different storm types per metric (Table 4). For runoff ratio, GSI in Brookside decreases runoff between roughly 10 and 20\%, with the most significant impacts occurring in low volume storms, and for longer duration events. For peak flow, all storms illustrate that GSI in Brookside reduces peak discharge rates, with reductions ranging from roughly 26 to $68 \%$ and the greatest reductions occurring in shorter and longer, or more spread out storms. The GSI arrangement in Brookside also reduced lag time between 50 and $80 \%$, corresponding to about 4-5 hours with the largest reductions occurring in short events regardless of precipitation volume. Lastly, Brookside GSI reduced flashiness for all storms, ranging from 56 to $70 \%$, with the largest reductions occurring in smaller and longer duration events. 
Table 4: Model Results of no GSI and Brookside GSI.

\begin{tabular}{|c|c|c|c|c|c|}
\hline $\begin{array}{l}\text { Variable } \\
\text { tested }\end{array}$ & $\begin{array}{l}\text { Rain } \\
\text { volume }\end{array}$ & $\begin{array}{l}\text { Storm } \\
\text { duration }\end{array}$ & $\begin{array}{l}\text { No } \\
\text { GSI }\end{array}$ & $\begin{array}{l}\text { Brookside } \\
\text { GSI }\end{array}$ & $\begin{array}{l}\text { Relative Difference } \\
(\% \Delta \text { from No GSI) }\end{array}$ \\
\hline \multirow[t]{4}{*}{ Runoff/Rain } & \multirow[t]{2}{*}{ Low } & Short & 0.23 & 0.20 & $-16.2 \%$ \\
\hline & & Long & 0.17 & 0.14 & $-19.6 \%$ \\
\hline & \multirow[t]{2}{*}{ High } & Short & 0.40 & 0.36 & $-9.8 \%$ \\
\hline & & Long & 0.36 & 0.32 & $-10.9 \%$ \\
\hline \multirow{4}{*}{$\begin{array}{l}\text { Peak flow } \\
(\mathrm{cms})\end{array}$} & \multirow[t]{2}{*}{ Low } & Short & 0.473 & 0.263 & $-44.4 \%$ \\
\hline & & Long & 0.395 & 0.128 & $-67.6 \%$ \\
\hline & \multirow[t]{2}{*}{ High } & Short & 1.138 & 0.840 & $-26.2 \%$ \\
\hline & & Long & 0.930 & 0.486 & $-47.8 \%$ \\
\hline \multirow{4}{*}{$\begin{array}{l}\text { Lag time } \\
\text { (hrs) }\end{array}$} & \multirow[t]{2}{*}{ Low } & Short & 5 & 1 & $-80.0 \%$ \\
\hline & & Long & 9 & 4 & $-55.6 \%$ \\
\hline & \multirow[t]{2}{*}{ High } & Short & 5 & 1 & $-80.0 \%$ \\
\hline & & Long & 6 & 3 & $-50.0 \%$ \\
\hline \multirow[t]{4}{*}{ Flashiness } & \multirow[t]{2}{*}{ Low } & Short & 0.222 & 0.086 & $-61.1 \%$ \\
\hline & & Long & 0.100 & 0.030 & $-70.0 \%$ \\
\hline & \multirow[t]{2}{*}{ High } & Short & 0.623 & 0.276 & $-55.7 \%$ \\
\hline & & Long & 0.218 & 0.094 & $-57.0 \%$ \\
\hline
\end{tabular}


The second scenario analysis, comparing synthetic designs of completely distributed and centralized GSI arrangements, shows similar trends to that of the No GSI vs. Brookside GSI comparison, except for lag time. As shown in Table 5, all scenarios illustrated that dispersed GSI decreases runoff ratio, ranging from 22 to $33 \%$, with the largest reduction occurring in the low volume, short duration event. For peak flow, all storms showed a consistent trend of a reduction in flow between 67 and 69\%. Distributed GSI exhibited an increase in lag time more so than centralized GSI for all storms, with the largest relative increases occurring for short duration events (500\% and $400 \%$ for low and high volume storms respectively), but the largest increase in time occurring for the low volume long duration event ( 8 hour increase). Lastly, dispersed was found to reduce flashiness for all storms with the greatest relative reductions occurring in high volume storms (between 60 and 62\% decrease) compared to low volume events (32 to $46 \%$ reductions). 
Table 5: Model Results of Centralized and dispersed GSI.

\begin{tabular}{|c|c|c|c|c|c|}
\hline $\begin{array}{l}\text { Variable } \\
\text { tested }\end{array}$ & $\begin{array}{l}\text { Rain } \\
\text { volume }\end{array}$ & $\begin{array}{l}\text { Storm } \\
\text { duration }\end{array}$ & $\begin{array}{c}\text { Centralized } \\
\text { GSI }\end{array}$ & $\begin{array}{l}\text { Dispersed } \\
\text { GSI }\end{array}$ & $\begin{array}{l}\text { Relative Difference } \\
(\% \Delta \text { from Cent. GSI) }\end{array}$ \\
\hline \multirow[t]{4}{*}{ Runoff/Rain } & Low & Short & 0.211 & 0.142 & $-32.6 \%$ \\
\hline & & Long & 0.150 & 0.117 & $-22.4 \%$ \\
\hline & High & Short & 0.378 & 0.294 & $-22.1 \%$ \\
\hline & & Long & 0.337 & 0.257 & $-23.8 \%$ \\
\hline \multirow{4}{*}{$\begin{array}{l}\text { Peak flow } \\
\text { (CMS) }\end{array}$} & Low & Short & 1.112 & 0.346 & $-68.9 \%$ \\
\hline & & Long & 0.585 & 0.185 & $-68.4 \%$ \\
\hline & High & Short & 3.542 & 1.208 & $-65.9 \%$ \\
\hline & & Long & 2.089 & 0.693 & $-66.8 \%$ \\
\hline \multirow{4}{*}{$\begin{array}{l}\text { Lag time } \\
\text { (hours) }\end{array}$} & Low & Short & 1 & 6 & $500 \%$ \\
\hline & & Long & 4 & 12 & $200 \%$ \\
\hline & High & Short & 1 & 5 & $400 \%$ \\
\hline & & Long & 3 & 7 & $133 \%$ \\
\hline \multirow[t]{4}{*}{ Flashiness } & Low & Short & 0.101 & 0.069 & $-31.5 \%$ \\
\hline & & Long & 0.034 & 0.019 & $-46.2 \%$ \\
\hline & High & Short & 0.354 & 0.134 & $-62.1 \%$ \\
\hline & & Long & 0.123 & 0.050 & $-59.7 \%$ \\
\hline
\end{tabular}




\section{Discussion and Conclusion}

Recall that in general, past research indicates that the GSI facilities will have a significant effect on reducing runoff that can cause flooding. Thomas et al.(2016) found that for $45 \mathrm{~km}^{2}$ watersheds in Beaver Creek, Iowa with distributed detention structures (GSI in short) reduced peak flows at outlets by as much as 17\%. Pennino et al. (2016) found that for catchments (with an average of $6 \mathrm{~km}^{2}$ ) "watersheds with greater amounts of GSI have less flashy hydrology, with 44\% lower peak runoff", but compared greatly varying watersheds (entire cities in the mid-Atlantic United States). Zellner et al. (2016) found that "with as little as $10 \%$ surface coverage, green infrastructure can greatly contribute to runoff capture in small storms" for $4 \mathrm{~km}^{2}$ catchments in Chicago. Despite ample research quantifying the impact of GSI, there still exists the needs to evaluate these structures at a catchment scale, to compare varying levels of precipitation events, to contrast arrangements and configurations, and to use multiple metrics to evaluate flow patterns that may lead to nuisance flooding.

In our research, the calibration of the SWMM model allowed us to perform two scenario analyses to answer these remaining questions. The calibration process in this study demonstrates that by limiting analysis to a subcatchment scale, uncertainties related to large watersheds can be eliminated, and model accuracy can be be attained (illustrated by significant NSE and PBIAS scores close to 1 and 0 respectively), which has been outlined as a gap in understanding across GSI literature (Bell et al. 2016, Refsgaard et al. 2016, Golden et al. 2017). Calibrated models can then be used to answer questions about various arrangements of GSI, and perhaps more importantly about the relative efficacy of 
infrastructure under different precipitation scenarios, something that is lacking in studies that measure GSI on a year or multiyear time scale (Ahiablame et al. 2013, Avelleneda et al. 2016). In an effort to satisfy scientific gaps in understanding associated with a lack of sub-catchment scale analysis on GSI, this research quantifies comparative efficacy of GSI arrangements without sacrificing accuracy by modeling outflow heavily influenced by external factors. At one end of the spectrum, small (structural) scale analyses typically cannot capture the compounding effects of multiple GSI or interactions between multiple structures (Golden et al. 2017). These localized analyses require formulaic methods to estimate larger scale impacts, which do not always account for non-linear relationships between number or size of facilities and runoff reduction potential (Loperfido et al. 2014). Conversely, modeling GSI at a large (regional) scale can measure results subject to variation in external factors such as changes in impervious surfaces, pipe infrastructure, or forest health that can influence hydrology despite attempts to create a controlled comparison (Loperfido et al. 2014, Pennino et al. 2016, Zellner et al. 2016).

The results of the first scenario analysis quantifies how the configuration of GSI in the Brookside neighborhood performed for four different metrics under four different types of precipitation events. In general, Brookside GSI appears to reduce flooding risk for all storms, with the greatest impact occurring in low volume and long duration precipitation events. This is evidenced by reductions in runoff ratio, peak flow, and flashiness indices, with the largest reductions occurring in low volume long duration storms for all three metrics. The findings with runoff ratio and peak flow suggest that as precipitation events increase in size and decrease in duration, soil and storage quickly becomes saturated, prohibiting infiltration, and redirecting runoff downstream rendering 
the structures less effective, a finding consistent with previous studies (Loperfido et al. 2014, Pennino et al. 2016, Zellner et al. 2016, Thomas et al. 2016, Bell et al. 2016). Although mostly consistent across storms (ranging $57-70 \%$ ), the trend exhibited with flashiness suggests small and long precipitation events are more likely to allow for GSI to function without becoming quickly overwhelmed and failing to capture additional runoff. This finding is supported by previous studies that have found flashiness--sometimes referred to hydrograph kurtosis--is either unaffected or dampened by GSI (Hood et al. 2007). Our findings in lag time are perhaps the least expected, which perhaps should be unsurprising given the effects of GSI on lag time are more contentious; while it is typically found to be delayed by GSI infrastructure (Hood et al. 2007, Davis et al.2008), previous studies have also found little to no change (Jarden et al. 2016). Either way, the finding that GSI reduces lag time is near bizarre, and may be a result of routing and reporting errors within SWMM. Errors aside, the only reasonable explanation for this phenomena is perhaps structures are designed in a way that reduces total runoff and peak flow by dampening flows at later periods of a rainfall-runoff event, thus shifting peak discharge to an earlier time and reducing lag time, although there is little evidence of this effect in previous studies.

One of the most frequently mentioned gaps in GSI literature is the need for research to compare different types of spatial arrangements of infrastructure, particularly as it relates to the dispersion of structures across a landscape (Lim et al. 2017). As noted in a review by Golden et al. (2017), there exist "future questions about optimal spatial configurations for [GSI] practices" and recommend "considering the placement and spatial configurations of [GSI] practices in the catchment. The second scenario seeks to 
answer this question by comparing distributed GSI (rain gardens, street side planters, infiltration strips) to centralized GSI (bioswales, detention ponds, and centralized detention pipes). In general we find that distributed infrastructure outperforms centralized for all four metrics, and to a greater extent for smaller, shorter duration storms (albeit for flashiness, large short storms exhibited the greatest relative reduction). This indicates that spatial location of infrastructure is key in reducing runoff volumes and peak discharges, and likely because flow paths are intercepted before runoff can amalgamate and exacerbate centralized facilities downstream. The findings that stronger reductions occur for smaller shorter events indicates that under small storms, small flow paths and volumes may be removed in their entirety. While many findings have found that GSI is more effective at lower precipitation volumes and duration (Mentens et al. 2006, Hood et al.2007, Chapman \& Horner 2010, Qin et al. 2013, Loperfido et al. 2014, Thomas et al. 2016), this finding suggests that the distributed structures may be the driving force behind the impact of GSI in these types of storms. Identifying that larger storms exhibit the greatest relative reduction in flashiness from centralized to dispersed arrangements is likely an outcome of the lack of an ability for large centralized facilities to absorb water quickly when overwhlemed with high intensity runoff. Furthermore, because the speed of runoff increases as it amalgamates, dispersed GSI may be better suited to separate flows that would otherwise combine and move at higher rates towards centralized facilities and system outfalls (Schueler 1987, Horner et al. 1994). All things considered, previous studies comparing the spatial dispersion of GSI are largely aligned with the findings of this paper. Fry et al. (2017) found that "spatial location has a significant impact on distributed BMP effectiveness, especially for smaller storm events where lower runoff 
volumes and fewer flow paths are intercepted by [GSI]." A study by Kim and Park (2016) find that "larger, less fragmented, and more connected landscape patterns are likely to [better] mediate the mean annual peak runoff" than more centralized designs. Our research supports these findings in suggesting that distributed structures are the driving force in GSI efficacy and may be better suited to mitigate nuisance flooding than centralized facilities and our findings corroborate these previous studies.

Understanding the types of spatial arrangements and climate scenarios under which GSI is most effective can not only lend direction to future academic and scientific research, but to city practitioners looking to guide planning efforts as they pertain to reducing flooding hazards. As with any municipality promoting development of new residential neighborhoods, careful consideration is spent identifying costs and benefits in investing in disaster risk reduction. Because GSI becomes increasingly more expensive as it is designed to capture greater volumes of runoff (Lim et al. 2016), there exist a need to quantify performance and identify the point in which it ceases to function effectively. This research shows that GSI is most effective when distributed across a landscape, and when designed with the purpose of reducing low volume, short duration precipitation events. Moreover, the results in this research can serve urban planners aiming to build risk resilient neighborhoods given future climate uncertainties, especially when projections may include increases in precipitation and flooding as with the city of Portland. Lastly, this study can serve as an exemplification for the importance of thinking critically about the spatial scale of analyzing hydrologic phenomena, and the relationship between runoff and connectivity of neighborhood systems. 


\section{Limitations and Future Recommendations}

While empirical outflow data and precipitation data were used at an hourly (relatively high temporal resolution) time scale, the highest resolution evaporation data was monthly, and the highest temperature data was daily. Future studies could likely improve the calibration of SWMM with hourly temperature daily, and/or hourly or daily evaporation data. While some potential errors were removed from the empirical outflow data, it is possible that malfunctions in the data loggers did not produce realistic results. Future studies might seek to identify additional potential errors and remove them before calibrating SWMM. Additionally, the precipitation data collected from the Portland Hydra Rainfall Network only provided rainfall in hundredths of an inch $(0.025 \mathrm{~cm})$ per hour. When scaled up to a .17 kilometer study area, the error associated with one hour's measurement could be as great as 400 cubic meters, leading to some potentially inaccurate rainfall volumes as inputs. Lastly, while this study aims to compare arrangement of GSI by delineating distributed and centralized facilities, it is not always the case that GSI can be categorized as one or the either. Future studies could provide a more encompassing assessment if a continuous set of GSI was organized by size and intended placement density. 


\section{References}

Ahiablame, L. M., Engel, B. A., Chaubey, I. (2012). Effectiveness of low impact development practices: Literature review and suggestions for future research. Journal of Water Air and Soil Pollution, 223, 4253-4273.

Ashley, R.M., Balmforth, D.J., Saul, A.J., Blanskby, J.D. (2005). Flooding in the future predicting climate change, risks and responses in urban areas. Water Science and Technology, 52(5), 265-273.

Avellaneda, P. M., Jefferson, A. J., Grieser, J. M. \& Bush, S. A. (2017). Simulation of the cumulative hydrological response to green infrastructure. Journal of Water Resources, 53(4), 3087-3101.

Baker, D. B., Richards, P.R., Loftus, T. T., Kramer, J. W. (2004). A New Flashiness Index: Characteristics and Applications to Midwestern Rivers and Streams. Journal of the American Water Resources Association. Paper No. 03095.

Bedan, E. S., \& Clausen, J. C. (2009). Stormwater runoff quality and quantity from traditional and low impact development watersheds. Journal of the American Water Resources Association, 40(2), 998-1008.

Bhaskar A.S., Hogan D.M., Archfield S.A., (2016). Urban base flow with low impact development. Hydrological Processes, 30, 3156-3171.

Beebe, C. (2016). Portland region nears 2.4 million residents, growing by 41,000 last year. Oregon Metro Times. Available Online. Last accessed 26 May 2018.

Bell, C. D., McMilan, S. K., Clinton, S. M., Jefferson, A. J. (2016). Hydrologic response to stormwater control measures in urban watersheds. Journal of Hydrology, 541(B), 1488-1500.

Blöschl, G. \& Sivapalan, M. (1995). Scale issues in hydrological modelling - A review. Hydrological Processes, 9 (3-4), 251-290.

Burns, M. J., Fletcher, T. D., Walsh, C. J., Ladson, A. R., \& Hatt, B. E. (2012). Hydrologic shortcomings of conventional urban stormwater management and opportunities for reform. Landscape and Urban Planning 105(3), 230-240.

Chang, H. (2007). Comparative streamflow characteristics in urbanizing basins in the Portland Metropolitan Area, Oregon, USA. Hydrolical Processes, 21(2), 211-222.

Chang, H. \& Franczyk, J. (2008). Climate change, land use change, and floods: Toward an integrated assessment. Geography Compass 2(5): 1549-1579. 
Chapman, C., \& Horner, R. R. (2010). Performance assessment of a street-drainage bioretention system. Water Environment Research, 82(2), 109-119.

City of Gresham Offices of Environmental Services and Water Resources: Katie Holzer, Torrey Lindbo, Deanna Foster. (2017). GIS, Land Cover, outflow, and development history data.

Combined Sewer Overflows. (2015). Department of Ecology, State of Washington. Available Online. Last accessed 26 May, 2018.

Cross Correlation Functions and Lagged Regressions. Penn State University Online Courses. Available Online. (2017). Last accessed 26 May, 2018.

Davis, A. P. (2008). Field performance of bioretention: hydrology impacts. Journal of Hydrologic Engineering, 13(2), 90-95.

Dickinson, R. (2017). Infiltration in InfoSWMM and InfoSWMM SA for Horton, Green Ampt and Curve Number Options. InfoSWMM: How to understand and calibrate hydrology and hydraulics models. Available Online. Last Accessed 6 October, 2018.

Demuzere, M., Orru, K., Heidrich, O., Olazabal, El, Geneletti, D., Orru, H., Bhave, A.G., Mittal, N., Feliu, E., Faehnle, M. (2014) Mitigating and adapting to climate change: Multi-functional and multi-scale assessment of green urban infrastructure. Journal of Environmental Management, 146. 107-115.

Deser, C., Phillips, A., Bourdette, V., Teng, H., (2012). Uncertainty in climate change projections: the role of internal variability. Climate Dynamics 38(3-4): 527-546

IPCC, 2014: Climate Change 2014: Synthesis Report. Contribution of Working Groups I, II and III to the Fifth Assessment Report of the Intergovernmental Panel on Climate Change [Core Writing Team, R.K. Pachauri and L.A. Meyer (eds.)]. IPCC, Geneva, Switzerland, 151 pp.

ISSN 0301-4797,Dietz, M. E. (2007). Low impact development practices: a review of current research and recommendations for future directions. Water Air, and Soil Pollution, 186(1-4), 351-363.

Farnsworth, R.K \& Thompson, E. S. (1982). Mean Monthly, Seasonal, and Annual Pan Evaporation for the United States. Office of Hydroology, National Weather Service, National Oceanic and Atmospheric Administration, United States Department of Commerce. Washington, D.C.

Fassman, E. A., \& Blackbourn, S. (2010). Urban runoff mitigation by a permeable pavement system over impermeable soils. Journal of Hydrologic Engineering, $15(6), 475-485$. 
Fletcher, T. D., Andrieu, H., \& Hamel, P. (2013). Understanding, management and modelling of urban Hydrology and its consequences for receiving waters: a state of the art. Advances in Water Resources, 51, 261-279.

Fry, T. J., \& Maxwell, R. M. (2017). Evaluation of distributed BMPs in an urban watershed - high resolution modeling for stormwater management. Hydrological Processes, 31(15), 2700-2712.

Gill, S.E., Handley, J.F., Ennos, A.R., Pauleit, S. (2007). Adapting Cities for Climate Change: The Role of the Green Infrastructure. Built Environment, 33(1), 115133(19).

Golden, H. E., \& Hoghooghi, N. (2017). Green infrastructure and its catchment-scale effects: an emerging science. Wiley Interdisciplinary Reviews: Water, 5(1), 254.

Granados-Olivas, A., Alatorre-Cejudo, L. C., Adams, D., Serra, Y. L., Esquivel-Ceballos, V. H., Vázquez-Gálvez, F. A., Giner, M. E. and Eastoe, C. (2016), Runoff Modeling to Inform Policy Regarding Development of Green Infrastructure for Flood Risk Management and Groundwater Recharge Augmentation along an Urban Subcatchment, Ciudad Juarez, Mexico. Journal of Contemporary Water Research \& Education, 159(1), 50-61.

Gregoire, B. G., \& Clausen, J. C. (2011). Effect of a modular extensive green roof on stormwater runoff and water quality. Ecological Engineering, 37(6), 963-969.

Hamel P., Daly, E., Fletcher, T.D. (2013). Source-control stormwater management for mitigating the impacts of Urbanization on base flow: a review. Journal of Hydrology, 485(2), 201-211.

Hirabayashi, Y., Mahendran, R., Koirala, S., Konoshima, L., Yamazaki, D., Watanabe, S., Kim, H., Kanae, S. (2013). Global Flood Risk Under Climate Change. Nature Climate Change, 3, 816-821

Hood, M. J., Clausen, J. C. \& Warner, G. S. (2007). Comparison of Stormwater Lag Times for Low Impact and Traditional Residential Development. Journal of the American Water Resources Association, 43(4), 1036-1046.

Horner, R.R., J.J. Skupien, E.H. Livingston and H.E. Shaver. (1994). Fundamentals of Urban Runoff Management: Technical and Institutional Issues. In cooperation with U.S. Environmental Protection Agency. Terrene Institute, Washington, D.C.

Hunt, W. F., \& Szpir, L. L. (2006). Permeable pavements, green roofs, and cisterns: Stormwater treatment practices for low-impact development. Urban Waterways, $A G, 588-606$. 
Jarden, K. M., Jefferson, A. J., \& Grieser, J. M. (2016). Assessing the effects of catchment-scale urban green infrastructure retrofits on hydrograph characteristics. Hydrological Processes, 30(10), 1536-1550.

Krebs, G., Kokkonen, T., Valtanen, M., Koivusalo H., \& Setäl, A. H. (2013). A high resolution application of a stormwater management model (SWMM) using genetic parameter optimization. Urban Water Journal, 10(6), 394-410.

Jayasooriya V., \& Ng, A. (2014). Tools for modeling of stormwater management and economics of green infrastructure Practices: a review. Water, Air, \& Soil Pollution, 225, 1-20.

Johnson Creek Watershed Action Plan: An Adaptive Approach. (2002). Johnson Creek Watershed Council. Available Online. Last accessed 26 May 2018.

Johnson Creek Watershed Characterization. (2005). Johnson Creek Watershed Council. Available Online. Last accessed 26 May 2018.

Jones, R.N. (2000). Managing Uncertainty in Climate Change Projections-Issues for Impact Assessment. Climatic Change, 45(3-4), 403-419.

Kim, H. W., \& Park, Y. (2016). Urban green infrastructure and local flooding: The impact of landscape patterns on peak runoff in four Texas MSAs. Applied Geography, 77, 72-81.

Lim, T. C, \& Welty, C. (2017). Effects of spatial configuration of imperviousness and green infrastructure networks on hydrologic response in a residential sewershed. Water Resources Research, 53(9), 8084-8104.

Loperfido, J.V., Noe, G. B., Jarnagin, S. T., Hogan, D. M. (2014). Effects of distributed and centralized stormwater best management practices and land cover on urban stream hydrology at catchment scale. Journal of Hydrology, 519(C), 2584-2595.

Matthews, T., Lo, A.Y., Byrne, J.A. (2015). Reconceptualizing Green Infrastructure for Climate Change Adaptation: Barriers to Adoption and Drivers for Uptake by Spatial Planners. Landscape and Urban Planning, 138. 155-163.

Mentens, J., Raes, D., \& Hermy, M. (2006). Green roofs as a tool for solving the rainwater runoff problem in the urbanized 21 st century? Landscape and urban planning, 77(3), 217-226

Miles, B., \& Band, L. E. (2015). Green infrastructure stormwater management at the watershed scale: urban variable source area and watershed capacitance. Hydrological Processes, 29(9), 2268-2274. 
Moore, T. L., Gulliver, J S., Stack, L., Simpson, M. H. (2016). Stormwater management and climate change: vulnerability and capacity for adaptation in urban and suburban contexts. Climatic Change, 138(3-4), 491-504.

Moriasi, D. N., Arnold, J. G., Van Liew, M. W., Bingner, R. L., Harmel, R. D., \& Veith, T. L. (2007). Model Evaluation Guidelines for Systematic Quantification of Accuracy in Watershed Simulations. American Society of Agricultural and Biological Engineers, 50(3): 885-900.

Noreen, Albin. 2015. Sustainability in Stormwater Management in a Changing Climate: A Case Study in Falkenberg, Sweden. Uppsats för avläggande av masterexamen $i$ naturvetenskap, 30(hp), 1-78.

Palmer, M.A., Liu, J. Matthews, J. H., Mumba, M., \& D’Odorico, P. (2015). Manage Water in a Green Way. Policy Forum on Water, 349(6248), 584-585.

Pennino, M. J., McDonald, R I., \& Jaffe, P. R. (2016). Watershed-scale impacts of stormwater green infrastructure on hydrology, nutrient fluxes, and combined sewer overflows in the mid-Atlantic region. Science of The Total Environment, 565(15), 1044-1053.

Pianosi, F., Beven, K., Freer, J., Hall, J. W., Rougier, J., Stephenson, D.B., \& Wagener, T. (2016). Sensitivity analysis of environmental models: A systematic review with practical workflow. Environmental Modelling \& Software, 79(), 214-232.

Portland HYDRA Rainfall Network. (2018). City of Portland Bureau of Environmental Services and United States Geographical Survey. Available online. Last accessed 15 November 2018.

Portland Sewer and Drainage Facilities Design Manual. (2007) Portland Bureau of Environmental Services. Available online. Last accessed 15 November 2018.

Portland Stormwater Management Facility Monitoring Report. (2013) Portland Bureau of Environmental Services. Available online. Last accessed 15 November 2018.

Portland Oregon and Multnomah County Climate Action Plan Progress Report. (2017). Portland 2015 Climate Action Plan. Available Online. Last Accessed 9 Nov 2018.

Portland Watershed Management Plan. (2005). City of Portland Bureau of Environmental Services. Available Online. Last accessed 26 May 2018.

Portland Stormwater Management Manual. (2016). City of Portland Bureau of Environmental Services. Available online. Last accessed 26 May 2018. 
Refsgaard, J. C., Højberg, A. L., He, X., Hansen, A. L., Rasmussen, S. H., \& Stisen, S. (2016). Where are the limits of model predictive capabilities?, Hydrological Processes, 30(26), 4956-4965.

Schueler, T.R. (1987). Controlling Urban Runoff: A Practical Manual for Planning and Designing Urban BMPs. Metropolitan Washington Council of Governments. Maryland Stormwater Design Manual. Maryland Department of the Environment. Baltimore, MD.

Selbig, W.R., \& Bannerman, R.T. (2008). A comparison of runoff quantity and quality from two small basins undergoing implementation of conventional- and lowimpact-development (LID) strategies: Cross Plains, Wisconsin, water years 19992005. U.S. Geological Survey Scientific Investigations Report, 2008-5008, viii, 57

Shuster, W. D., Bonta, J., Thurston, H., Warnemuende, E., \& Smith, D.R. (2005). Impacts of impervious surface on watershed hydrology: a review. Urban Water Journal, 2(4), 263-275.

Thomas, N. W., Antonio, A. A., Schilling, K. E., \& Weber, L. J. (2016). Evaluating the efficacy of distributed detention structures to reduce downstream flooding under variable rainfall, antecedent soil, and structural storage conditions. Advances in Water Resources, 96, 74-87.

Vogel J. R., Morre, T. L., Coffman, R. R., Rodie, S. N., Hutchinson, S.L., McDonough, K. R., McLemore, A. J., \& McMaine, J. T. (2015). Critical review of technical questions facing low impact development and green infrastructure: a perspective from the Great Plains. Water \& Environmental Resources, 87(9), 849-862.

Wang, X., Shuster, W., Pal, C., Buchberger, S., Bonta, J., \& Avadhanula, K. (2010). Low impact development design-integrating suitability analysis and site planning for reduction of post-development stormwater quantity. Journal of Sustainability, 2(8), 2467-2482.

Wang, M., Zhang, D. Q., Adhityan, A., Ng, W. J., Dong, J., \& Tan, S.K. (2016). Assessing cost-effectiveness of bioretention on stormwater in response to climate change and urbanization for future scenarios. Journal of Hydrology, 543(B), 423432.

Wainwright J., Turnbull L., Ibrahim T. G., Lexartza-Artza I., Thornton, S. F., \& Brazier, R. E. (2011). Linking environmental Régimes, space and time: interpretations of structural and functional connectivity. Geomorphology, 126(3-4), 387-404.

Wood, E. F., Sivapalan, M., Beven, K., \& Band, L. E. (1988). Effects of spatial variability and scale with implications to hydrologic modeling. Journal of Hydrology, 102, 29-47. 
Zellner, M., Massey, D., Minor, E., \& Gonzalez-Meler, M. (2016). Exploring the effects of green infrastructure placement on neighborhood-level flooding via spatially explicit simulations. Computers, Environment and Urban Systems, 59, 116-128.

Zimmerman, M.J., Barbaro, J.R., Sorenson, J.R., \& Waldron, M.C. (2010). Effects of selected low-impact-development (LID) techniques on water quality and quantity in the Ipswich River Basin, Massachusetts - field and modeling studies. U.S. Geological Survey Scientific Investigations Report, 2010-5007, xiv, 110-113. 
Appendix: Sensitivity using proportions of change in output to input

\begin{tabular}{|c|c|c|c|c|c|c|c|}
\hline $\begin{array}{l}\text { Quantitative } \\
\text { Parameter }\end{array}$ & $-30 \%$ & $-20 \%$ & $-10 \%$ & $+10 \%$ & $+20 \%$ & $+30 \%$ & Mean \\
\hline $\begin{array}{l}\text { Monthly Evap } \\
\text { Constants } \\
\text { (Default } \mathbf{0 . 1} \text { in/day) }\end{array}$ & $-20.9 \%$ & $-19.2 \%$ & $-19.3 \%$ & $-18.6 \%$ & $-18.8 \%$ & $-18.6 \%$ & $-19.2 \%$ \\
\hline $\begin{array}{l}\text { Imperv. } \\
\text { Depression } \\
\text { Storage } \\
\text { (Default 0.05) }\end{array}$ & $-6.2 \%$ & $-5.8 \%$ & $-5.5 \%$ & $-5.1 \%$ & $-5.1 \%$ & $-5 \%$ & $-5.4 \%$ \\
\hline $\begin{array}{l}\text { \% Zero } \\
\text { Impervious } \\
\text { (Default 25\%) }\end{array}$ & $3.2 \%$ & $3.2 \%$ & $3.2 \%$ & $3.2 \%$ & $3.2 \%$ & $3.2 \%$ & $3.2 \%$ \\
\hline $\begin{array}{l}\text { Conductivity } \\
\text { Constant } \\
\text { (Default 0.5) }\end{array}$ & $-2.6 \%$ & $-2.5 \%$ & $-2.5 \%$ & $-2.5 \%$ & $-2.5 \%$ & $-2.4 \%$ & $-2.5 \%$ \\
\hline $\begin{array}{l}\text { Width of } \\
\text { Overland Flow } \\
\text { (Default 100) }\end{array}$ & $1.6 \%$ & $1.4 \%$ & $1.3 \%$ & $1.2 \%$ & $1.1 \%$ & $1.0 \%$ & $1.2 \%$ \\
\hline $\begin{array}{l}\text { Manning's N } \\
\text { (Impervious) } \\
\text { (Default 0.012) }\end{array}$ & $-0.9 \%$ & $-0.6 \%$ & $-1.3 \%$ & $-1.2 \%$ & $-1.2 \%$ & $-1.1 \%$ & $-1.0 \%$ \\
\hline
\end{tabular}

